\title{
COMPLEXOS METÁLICOS COM O HERBICIDA GLIFOSATO: REVISÃO
}

\author{
Cláudia F. B. Coutinho* e Luiz Henrique Mazo \\ Instituto de Química de São Carlos, Universidade de São Paulo, CP 780, 13560-970 São Carlos-SP
}

Recebido em 27/9/04; aceito em 22/3/05; publicado na web em 24/8/05

\begin{abstract}
METALLIC COMPLEXES WITH GLYPHOSATE: A REVIEW. We present studies involving metallic ions and the herbicide glyphosate. The metallic complexes of $\mathrm{Cu}(\mathrm{II}), \mathrm{Zn}(\mathrm{II}), \mathrm{Mn}(\mathrm{II}), \mathrm{Ni}(\mathrm{II}), \mathrm{Cd}(\mathrm{II}), \mathrm{Pb}(\mathrm{II}), \mathrm{Cr}(\mathrm{III}), \mathrm{Fe}(\mathrm{III}), \mathrm{Co}(\mathrm{III})$, ammonium, sodium, $\mathrm{Ag}(\mathrm{I})$, alkaline earth metals and of some lanthanides ions are described. The complexes are discussed in terms of their synthesis, identification, stability and structural properties, based on data from the current literature.
\end{abstract}

Keywords: metallic complexes; glyphosate; transition metal ions.

\section{INTRODUÇÃO}

O glifosato [N-(fosfonometil)glicina] é um herbicida sistêmico, pós-emergente e não seletivo largamente utilizado na agricultura ${ }^{1}$. O glifosato pertence ao grupo químico dos aminoácidos fosfonados e tal como seu precursor, a glicina, apresenta comportamento zwiteriônico, com separação de duas cargas em pH neutro, uma positiva no grupo amino e uma negativa no grupo fosfonato. A fórmula estrutural do glifosato é mostrada na Figura 1.<smiles>O=C(O)CNCP(=O)(O)O</smiles>

Figura 1. Fórmula estrutural do glifosato

O modo de ação do glifosato consiste na alteração de diferentes processos bioquímicos vitais nas plantas, como a biosíntese de aminoácidos, proteínas e ácidos nucléicos ${ }^{2}$. O herbicida é absorvido pelo tecido vivo e translocado, via floema, através da planta para raízes e rizomas, e sua ação inibe enzimas específicas como a enolpiruvil shikimato-3-fosfato sintase (EPSP) suspendendo a síntese de aminoácidos aromáticos ${ }^{1,3}$. As plantas tratadas com glifosato morrem lentamente, em poucos dias ou semanas, e devido ao transporte por todo o sistema, nenhuma parte da planta sobrevive.

Em condições normais, a enzima EPSP catalisa, na planta, a reação que envolve a transferência do enolpiruvil do fosfoenolpiruvato (PEP) para o shikimato-3-fosfato (S3P), formando 5enolpiruvil shikimato-3-fosfato (EPSP) e fosfato inorgânico $\left(\mathrm{P}_{\mathrm{i}}\right)$. Esta reação está representada na Figura 2. Numerosos estudos usando NMR, fluorescência e calorimetria de varredura diferencial demonstraram que o glifosato forma preferencialmente um complexo ternário estável com a enzima EPSP sintase e S3P (EPSPS3P-glifosato). Esse provável complexo ternário representa a forma atualmente aceita como responsável pela atividade do herbicida ${ }^{4}$.

Na maioria dos casos, o glifosato não é metabolizado pela planta, razão pela qual não apresenta seletividade. Quando aplicado diretamente no solo apresenta baixa atividade, devido à degradação microbiológica para produtos não fitotóxicos ${ }^{5}\left(\mathrm{CO}_{2}, \mathrm{PO}_{4}^{-3} \mathrm{e}\right.$

*e-mail: claudiabreda@iqsc.usp.br
$\mathrm{NH}_{3}$ ) e à grande adsorção pelos constituintes do solo .

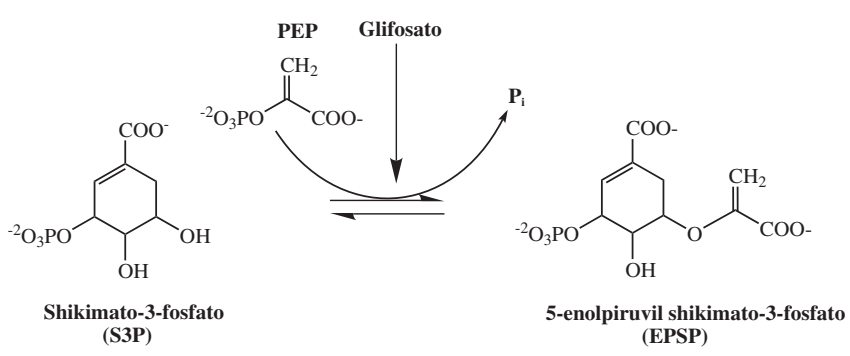

Figura 2. Sexto estágio da etapa que envolve a transferência do enolpiruvil do PEP para o $S 3 P$

O grupo fosfonato R-PO $(\mathrm{OH})_{2}$ do composto tem a habilidade de formar complexos fortes com metais. Todos os processos de adsorção, fotodegradação e biodegradação dos fosfonatos são modificados pela presença de íons metálicos, devido à formação de complexos solúveis e não solúveis ${ }^{7}$.

Além do grupo fosfonato, o herbicida possui outros dois grupos funcionais (amino e carboxilato) que podem se coordenar fortemente com íons metálicos, especialmente com os de transição em $\mathrm{pH}$ próximo de neutro onde os grupos carboxilato e fosfonato estão desprotonados. A habilidade para se coordenar como um ligante tridentado coloca o glifosato numa posição privilegiada entre os herbicidas ${ }^{8}$.

A presença de água dura, contendo cátions como ferro, zinco, cálcio e magnésio, na solução "spray" de glifosato, pode resultar na formação de sais complexos insolúveis, que não são absorvidos pelas plantas, reduzindo a eficácia da aplicação do composto ${ }^{9}$. Wills e McWhorter ${ }^{10}$ observaram que a adição de cátions monovalentes, como amônio, sódio e potássio, na solução de glifosato resultou no aumento da sua fitotoxicidade. Entretanto, a adição de cátions di e trivalentes, como zinco(II) e ferro(III), diminuiu a atividade do herbicida.

Segundo Sprankle e colaboradores ${ }^{11}$, o glifosato apresenta uma seqüência de equilíbrios com as seguintes constantes de dissociação ácida (pKa): <2,0, 2,6, 5,6 e 10,6, como mostrado na Figura 3. Em $\mathrm{pH}$ abaixo de 2,0 o glifosato apresenta carga líquida positiva, o que contribui para sua adsorção à argila e matéria orgânica do solo, que possui carga negativa. Em $\mathrm{pH}$ acima de 2,6 o glifosato tem carga zero e o número de cargas negativas aumenta com o aumento 
do $\mathrm{pH}$. Em $\mathrm{pH}$ acima de 12, praticamente todo o glifosato está na forma trianiônica.

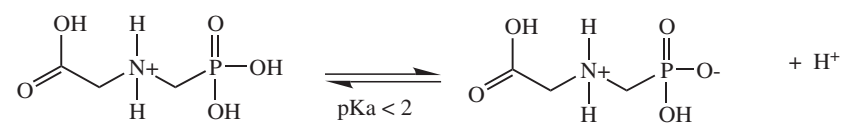

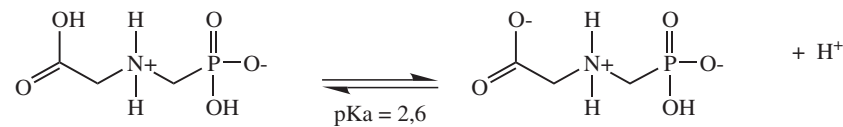<smiles>O=C(O)C[NH2+]C[NH2+]C[PH](=O)(O)OP(=O)([O-])O</smiles><smiles>O=C(O)C[NH2+]CP(=O)(O)O</smiles>

Figura 3. Equilíbrios e constantes de dissociação do herbicida glifosato

Uma revisão da literatura mostra que o maior número de estudos de formação de complexos com glifosato está relacionado aos complexos de íons cobre(II), sendo interessante notar que apesar da grande importância do composto, tanto como ligante, como o seu interesse comercial e em química ambiental (aplicação nas culturas de transgênicos), poucos trabalhos relacionados com a formação de complexos de outros íons metálicos de transição são encontrados.

\section{COMPLEXOS DE COBRE(II) COM GLIFOSATO}

Os complexos de cobre(II) com glifosato são amplamente estudados, devido à importância do íon cobre para plantas e animais. Além disso, o íon cobre se liga nas proteínas formando metaloproteínas ("proteínas azuis") ${ }^{12}$ e, também, porque a concentração deste íon no solo e na água vem aumentando gradativamente com o uso de fungicidas, fertilizantes, descarte inadequado de esgotos e outros resíduos que contêm este metal(II) ${ }^{13,14}$. Embora em baixas concentrações o cobre(II) seja essencial, em concentrações maiores torna-se tóxico para plantas ${ }^{12}$. Na cultura de soja, por ex., a deficiência de íons cobre causa necrose das folhas e, por outro lado, o excesso causa clorose das mesmas.

\section{Síntese e caracterização estrutural}

Em 1988, Subramaniam e Hoggard ${ }^{8}$ sintetizaram o complexo cristalino azul $\left[\mathrm{Cu}(\mathrm{HL}) \mathrm{H}_{2} \mathrm{O}\right] .0,4 \mathrm{CuO}$, pouco solúvel em água, álcoois, acetonitrila e dimetilformamida, misturando quantidades equimolares de glifosato e $\mathrm{Cu}(\mathrm{II})$. A caracterização do complexo foi feita por difração de Raios-X, e a forma sólida do complexo de cobre possui uma co-cristalização de $\mathrm{CuO}$, que foi evidenciada através de um pico de $\mathrm{CuO}$ puro na difração de Raios- $\mathrm{X}^{15}$. Este complexo também foi caracterizado por IR e as frequiências obtidas por Subramaniam e Hoggard $^{8}$ são apresentadas na Tabela 1.

Tabela 1. Freqüências de IR $\left(\mathrm{cm}^{-1}\right)$ para o complexo cobre(II)glifosato. Reproduzida da ref. 8, com permissão da ACS

\begin{tabular}{lcc}
\hline Modo & $\mathrm{H}_{3} \mathrm{~L}$ & {$\left[\mathrm{Cu}(\mathrm{HL}) \mathrm{H}_{2} \mathrm{O}\right] \cdot 0,4 \mathrm{CuO}$} \\
\hline$v_{\text {as }}\left(\mathrm{CO}_{2}\right)$ & 1734 & 1634 \\
$\delta \mathrm{NH}_{2}$ & 1563 & $*$ \\
$\nu_{\mathrm{s}}\left(\mathrm{PO}_{3}\right)$ & 981 & 1002 \\
$v_{\text {as }}\left(\mathrm{PO}_{3}\right)$ & 1094 & 1106
\end{tabular}

*Encoberta pelo forte estiramento da banda carboxilato

\section{Constante de estabilidade e produto de solubilidade}

A constante de estabilidade do complexo de cobre sintetizado por Subramaniam e Hoggard ${ }^{8}$ foi determinada em 1978, por Madsen e colaboradores ${ }^{16}$. A constante referente ao complexo metálico 1:1 (Cu(II):glifosato, $\log \mathrm{K}=11,92)$ foi obtida através de titulação potenciométrica, em força iônica $0,1 \mathrm{M}\left(\mathrm{KNO}_{3}\right)$ a $25^{\circ} \mathrm{C}$. Madsen e colaboradores ${ }^{16}$ também determinaram as constantes de estabilidade de outros complexos metálicos com o glifosato, que são apresentadas na Tabela 2 para fins de comparação.

Tabela 2. Constantes de estabilidade (log K) de complexos metálicos com glifosato

\begin{tabular}{lcccc}
\hline $\mathrm{Cu}(\mathrm{II})$ & $\mathrm{Zn}(\mathrm{II})$ & $\mathrm{Mn}(\mathrm{II})$ & $\mathrm{Ca}(\mathrm{II})$ & $\mathrm{Mg}(\mathrm{II})$ \\
\hline 11,92 & 8,4 & 5,53 & 3,25 & 3,25 \\
\hline
\end{tabular}

Sundaram e Sundaram ${ }^{13}$ determinaram o produto de solubilidade (Kps) de complexos de glifosato com vários metais, entre eles o cobre(II), que foi sintetizado como descrito por Subramaniam e Hoggard ${ }^{8}$. O produto de solubilidade do complexo $\left[\mathrm{Cu}(\mathrm{HL}) \mathrm{H}_{2} \mathrm{O}\right] .0,4 \mathrm{CuO}$ foi determinado em tampão fosfato $\mathrm{pH} 7,0$ e também em extratos de diferentes tipos de solo. Os valores de Kps obtidos para este e outros complexos metálicos com glifosato estão representados na Tabela 3.

$\mathrm{O}$ valor de Kps encontrado foi baixo, ou seja, o complexo $\left[\mathrm{Cu}(\mathrm{HL}) \mathrm{H}_{2} \mathrm{O}\right] .0,4 \mathrm{CuO}$ é pouco solúvel, tal como a maioria dos complexos metálicos com glifosato, obtidos por Subramaniam e Hoggard ${ }^{8}$.

\section{Estudos termodinâmicos e espectrofotométricos}

Complexos de cobre(II) com glifosato com diferentes extensões de protonação foram estudados por Daniele e colaboradores ${ }^{1}$. Tais complexos foram investigados em solução aquosa por meio

Tabela 3. Produtos de solubilidade (Kps) para complexos metálicos com glifosato em água e em diferentes tipos de solo

\begin{tabular}{|c|c|c|c|c|}
\hline Complexo & Água & Solo arenoso & Areia & Solo argiloso \\
\hline$\left[\mathrm{Cu}(\mathrm{HL}) \cdot \mathrm{H}_{2} \mathrm{O}\right] \cdot 0,4 \mathrm{CuO}$ & $2,7 \times 10^{-13}$ & $2,6 \times 10^{-13}$ & $2,9 \times 10^{-13}$ & $2,4 \times 10^{-13}$ \\
\hline $\mathrm{Zn}(\mathrm{HL})$ & $5,62 \times 10^{-10}$ & $3,03 \times 10^{-10}$ & $5,31 \times 10^{-10}$ & $1,91 \times 10^{-10}$ \\
\hline $\mathrm{Mn}(\mathrm{HL})$ & $0,955 \times 10^{-6}$ & $0,411 \times 10^{-6}$ & $0,977 \times 10^{-6}$ & $0,0924 \times 10^{-6}$ \\
\hline$\left[\mathrm{Fe}(\mathrm{L})\left(\mathrm{H}_{2} \mathrm{O}\right)_{2}\right] \cdot 1,25 \mathrm{H}_{2} \mathrm{O}$ & $5,62 \times 10^{-15}$ & $5,51 \times 10^{-15}$ & $5,77 \times 10^{-15}$ & $5,42 \times 10^{-15}$ \\
\hline$[\mathrm{Mg}(\mathrm{HL})] \cdot 2,25 \mathrm{H}_{2} \mathrm{O}$ & $0,933 \times 10^{-4}$ & $0,311 \times 10^{-4}$ & $0,989 \times 10^{-4}$ & $0,0885 \times 10^{-4}$ \\
\hline$[\mathrm{Ca}(\mathrm{HL})] \cdot 2,25 \mathrm{H}_{2} \mathrm{O}$ & $1,07 \times 10^{-4}$ & $0,426 \times 10^{-4}$ & $1,33 \times 10^{-4}$ & $0,115 \times 10^{-4}$ \\
\hline
\end{tabular}


de medidas de $\mathrm{pH}$, calorimetria e espectrofotometria na região do visível. Alguns parâmetros termodinâmicos e espectrofotométricos referentes aos complexos são mostrados na Tabela 4 .

Algumas considerações estruturais foram feitas a partir dos dados termodinâmicos e espectrofotométricos. Os complexos não apresentaram $\lambda_{\text {máx }}>700 \mathrm{~nm}$, indicando que a coordenação com dois nitrogênios no plano equatorial não ocorre nos complexos de cobre(II) com glifosato.

Para o complexo 1:2 $\left(\mathrm{CuL}_{2}^{-4}\right)$, sugeriu-se que os nitrogênios dos grupos amina se coordenam um na posição axial e o outro, na posição equatorial. Os dados termodinâmicos e espectrofotométricos mostraram que uma das duas moléculas de glifosato se liga ao íon cobre através do nitrogênio na posição axial, com um oxigênio carregado negativamente ocupando a quarta posição no plano equatorial.

Já para os complexos 1:1 (CuHL e $\mathrm{CuL}^{-}$), foi sugerido que a complexação ocorre com a formação de dois anéis quelatos. A partir de modelos moleculares ${ }^{14}$ concluiu-se que os três sítios de coordenação do glifosato não se dispõem numa conformação tetraédrica ou quadrado-planar ao redor do cobre(II), mas sim, ocupam três das seis posições de um octaedro distorcido (Distorção de JahnTeller) ${ }^{12}$, onde a molécula de glifosato forma com o cobre(II) dois anéis quelatos de cinco membros orientados no plano equatorial; completando este octaedro, ligam-se três moléculas de água: uma fechando o plano equatorial e as outras duas ocupando os vértices do octaedro. As estruturas dos complexos $\mathrm{CuHL}^{2} \mathrm{CuL}^{-}$são essencialmente as mesmas, diferindo somente na protonação do grupo fosfonato. A representação da estrutura molecular do complexo CuLestá na Figura 4.

Glass², em 1984, propôs um procedimento diferente para estudar a complexação de cobre(II) com glifosato. Neste procedimen-

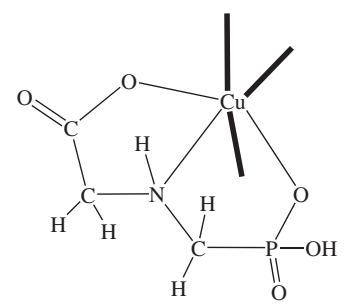

Figura 4. Estrutura molecular do complexo $\mathrm{CuL}^{-}$ to, soluções com diferentes concentrações do composto foram misturadas a uma quantidade fixa de óxido de cobre(II). Estas misturas foram agitadas, à temperatura ambiente, centrifugadas e filtradas. O desenvolvimento da coloração azul nas soluções de glifosato com íons cobre foi uma evidência da formação de complexo. $\mathrm{O}$ pH final de cada solução foi medido observando-se o aumento de 2 a 3 unidades no valor do $\mathrm{pH}$ inicial, o que evidencia o consumo de íons hidrogênio durante o processo de dissolução-complexação. Schindler ${ }^{17}$ demonstrou que a solubilidade do óxido de cobre é dependente de íons hidrogênio, como ilustrado abaixo:

$\mathrm{CuO}_{(\mathrm{s})}+2 \mathrm{H}^{+} \rightarrow \mathrm{Cu}(\mathrm{II})+\mathrm{H}_{2} \mathrm{O}$

O efeito do $\mathrm{pH}$ no sistema glifosato-cobre não foi explicado por Glass ${ }^{2}$, entretanto, foi proposto que o herbicida interagia de alguma maneira com o óxido de cobre (na interface sólido-liquido), já que a concentração de cobre(II) na solução aumentava à medida que aumentava a concentração do herbicida.

Estas soluções apresentaram uma banda na região do UV com um $\lambda_{\text {máx }}$ em $226 \mathrm{~nm}$. Esta banda de transição foi interpretada como banda de transferência de carga, ou seja, resultante da transferência de elétron de um dos grupos do glifosato para o metal, provavelmente a amina secundária. No espectro na região do visível a banda entre 700 e $800 \mathrm{~nm}$ foi atribuída à transição d-d, típica dos complexos de cobre.

O estudo eletroquímico de complexos metálicos com glifosato é pouco explorado e Glass ${ }^{2}$ foi um dos únicos que se propôs estudar o comportamento destes complexos. Alguns complexos de metais de transição, entre eles o complexo de cobre(II), foram caracterizados através de polarografia de pulso diferencial (DDP), usando eletrodo gotejante de mercúrio (DME). Foram preparadas soluções aquosas de complexos com diferentes razões cobre(II)/glifosato, usando 0,1 $\mathrm{M}$ de $\mathrm{KCl}$ como eletrólito suporte. Os polarogramas obtidos registraram duas ondas polarográficas, uma referente ao cobre(II) livre e a outra ao cobre(II) complexado com o herbicida. O glifosato mostrou-se polarograficamente inativo, como relatado por Bronstad e Friestad $^{18}$. O cobre(II) livre produziu uma onda polarográfica com potencial de meia-onda de $-0,09 \mathrm{~V}$ e na presença de glifosato um potencial de meia-onda de $-0,26 \mathrm{~V}$ vs ECS. A redução do complexo de cobre(II) mostrou-se dependente do $\mathrm{pH}$. Os dados polarográficos encontrados por Glass estão na Tabela 5.

Tabela 4. Parâmetros termodinâmicos e espectrofotométricos dos complexos de cobre(II) com glifosato

\begin{tabular}{lccccc}
\hline Complexo & $-\Delta \mathrm{G}^{\mathrm{o}}\left(\mathrm{kJ} \mathrm{mol}^{-1}\right)$ & $\Delta \mathrm{H}^{\mathrm{o}}\left(\mathrm{kJ} \mathrm{mol}^{-1}\right)$ & $\Delta \mathrm{S}^{\circ}\left(\mathrm{J} \cdot \mathrm{K}_{\mathrm{mol}}^{-1}\right)$ & $\Delta \mathrm{C}_{\mathrm{p}}{ }^{\circ}\left(\mathrm{kJ} \mathrm{K}^{-1} \mathrm{~mol}^{-1}\right)$ & $\lambda$ \\
\hline $\mathrm{CuHL}$ & 89,7 & $-5,5 \pm 1,3$ & 286,3 & 0,80 & 745 \\
$\mathrm{CuL}^{-}$ & 67,4 & $-9,5 \pm 2,1$ & 192,2 & 0,50 & 730 \\
$\mathrm{CuL}_{2}^{-4}$ & 90,6 & $-30,0 \pm 3,5$ & 195,3 & 0,90 & 715 \\
\hline
\end{tabular}

Tabela 5. Potenciais de meia-onda $\left[-\left(\mathrm{E}_{1 / 2}\right)\right]$ e correntes limites $\left(\mathrm{i}_{\mathrm{d}}\right)$ para a redução polarográfica de cobre(II) livre e complexado com glifosato. Reproduzida da ref. 2, com permissão da ACS

\begin{tabular}{|c|c|c|c|c|c|c|}
\hline $\begin{array}{l}\text { Concentração de } \\
\text { cobre(II) }(\mathrm{mM})\end{array}$ & $\begin{array}{l}\text { Concentração de } \\
\text { glifosato }(\mathrm{mM})\end{array}$ & $\mathrm{pH}$ & $-\left(E_{1 / 2}\right)_{M}{ }^{a} / V$ & $\mathrm{i}_{\mathrm{d}} / \mathrm{mA}$ & $-\left(E_{1 / 2}\right)_{C}^{b} / V$ & $\mathrm{i}_{\mathrm{d}} / \mathrm{mA}$ \\
\hline 0,25 & 0,0 & 5,2 & 0,09 & 0,40 & - & - \\
\hline 1,0 & 2,5 & 11,0 & ND & - & 0,26 & 0,05 \\
\hline 1,0 & 5,0 & 11,0 & ND & - & 0,26 & 0,05 \\
\hline 1,0 & 10,0 & 11,0 & ND & - & 0,26 & 0,14 \\
\hline
\end{tabular}

-( $\left.\mathrm{E}_{1 / 2}\right)$ x SCE (Eletrodo de calomelano saturado); ${ }^{a}$ potencial de meia-onda do cobre(II) livre e ${ }^{\mathrm{b}}$ complexado com glifosato; ND: nãodetectável. 


\section{Sistema cobre(II)-glifosato no solo}

Quando aplicado no solo, o glifosato exibe baixa atividade herbicida devido à degradação de sua estrutura por microrganismos para produtos não-fitotóxicos ${ }^{11} \mathrm{e}$, também, devido ao alto grau de adsorção nos constituintes do solo. O glifosato compete com fosfato inorgânico por sítios de adsorção no solo e em sedimen$\operatorname{tos}^{19,20}$, ligando-se ao solo por um mecanismo similar ao do fosfato inorgânico. Matéria orgânica ${ }^{21}$, hidróxidos amorfos de ferro e alumínio $^{22}$ e óxidos férricos ${ }^{23}$ são possíveis sítios de adsorção. Segundo Torstensson ${ }^{24}$, a ligação do glifosato no solo pode ser fortemente influenciada pela presença de cátions dissociados, mas é relativamente independente do $\mathrm{pH}$. Entretanto, alguns autores ${ }^{25,26}$ observaram que a adsorção de glifosato por argilas e óxidos geralmente diminui com o aumento do $\mathrm{pH}$ do sistema.

A adsorção de glifosato em solos contendo teores elevados de matéria orgânica e argila ocorre muito mais rapidamente que a degradação microbiológica, sendo que a perda da atividade herbicida é devida, principalmente, à formação de complexos metálicos. Morillo e colaboradores ${ }^{27}$ conduziram uma série de experimentos relatando a interação entre cobre(II) e glifosato no solo. Em 1994, estes autores propuseram-se a estudar o sistema cobre(II)-glifosato por voltametria de redissolução anódica e a influência do herbicida sobre a adsorção de cobre(II) em montmorillonita ${ }^{27}$ (aluminosilicato hidratado, composto de alumínio, magnésio e cálcio hidratado, pertencente à classe dos argilominerais). O complexo apresentou comportamento lábil e a partir dos dados obtidos com a equação de Freundlich ${ }^{28}$ concluiu-se que o herbicida apresenta um baixo grau de heterogeneidade, que pode ser atribuído à existência de dois grupos complexantes (carboxilato e fosfonato). A adsorção de cobre(II) no solo foi drasticamente diminuída na presença do herbicida, devido a alguns fatores, como a diminuição da concentração de cobre(II) livre, causada pela formação do complexo $\mathrm{Cu}$ (II)glifosato $\left(\mathrm{CuL}^{-}\right.$e $\left.\mathrm{CuHL}\right)$, ou devido à superfície carregada do glifosato sobre montmorillonita estar obstruindo a adsorção interlamelar de $\mathrm{Cu}(\mathrm{II})$, além do efeito competitivo entre prótons e $\mathrm{Cu}(\mathrm{II})$ por posições interlamelares.

Morillo e colaboradores ${ }^{6,29}$ observaram que a adsorção de glifosato em três diferentes tipos de solo não resulta da capacidade de troca catiônica ou conteúdo mineral dos solos, mas sim, do conteúdo de óxidos de ferro, alumínio e matéria orgânica. Eles observaram que a presença de cobre(II) nas soluções aumentou a adsorção de glifosato devido a alguns fatores, como a maior habilidade do complexo formado para se adsorver no solo quando comparada com a do glifosato livre, sendo que a adsorção de glifosato livre poderia acontecer em sítios onde o cobre(II) estava previamente adsorvido, atuando como ponte entre solo e glifosato. Notaram ainda que, quando o cobre(II) estava inicialmente presente, o $\mathrm{pH}$ da solução diminuiu e a adsorção de glifosato aumentou, já que valores de pH mais baixos conduzem à formação de espécies de glifosato com menos cargas negativas (ou seja, carga líquida mais positiva), que são mais facilmente adsorvidas na superfície do solo, que tem predomínio de cargas negativas.

No final da década de 1990, Maqueda e colaboradores ${ }^{30}$ estudaram a adsorção de cobre(II) e glifosato em complexos de ácidos fúlvicos. Neste estudo, foi observada uma grande adsorção de glifosato no complexo metálico de ácidos fúlvicos na ausência de cobre(II) e uma diminuição drástica desta adsorção com a presença do íon metálico na solução, devido à formação de um forte complexo metálico com o cobre(II) adicionado ou com $\mathrm{Fe}$ e $\mathrm{Al}$ desorvidos do complexo de ácido fúlvico. Tais complexos possuem menor tendência em se adsorver que o glifosato livre. A desorção de $\mathrm{Fe}$ e $\mathrm{Al}$ foi mais intensa quanto maior a concentração de cobre(II) e glifosato, devido à diminuição do pH de equilíbrio e substituição de íons de $\mathrm{Fe}$ e Al por cobre(II) no complexo de ácido fúlvico e, também, pela troca do glifosato por ácido fúlvico no complexo de cobre. Entretanto, quanto maior a concentração de glifosato maior a adsorção de cobre(II), uma vez que a formação de complexos de Fe e $\mathrm{Al}$ com glifosato origina sítios vazios no complexo metálico com ácidos fúlvicos, facilitando a adsorção de cobre(II).

Undabeytia e colaboradores ${ }^{31}$ mostraram a interação do glifosato com cobre(II) em complexos húmicos. Espectros de ressonância paramagnética eletrônica (EPR) de soluções com ácidos húmicos na presença de cobre(II) indicaram a formação de complexos. Quando o glifosato foi adicionado nas soluções, originou espectros que mostravam a presença de um complexo com baixo peso molecular, sendo este espectro muito semelhante ao do complexo de cobre(II) com glifosato. Como relatado por $\mathrm{McBride}^{32}$, o glifosato possui a habilidade de complexar e remover o cobre(II) ligado aos complexos húmicos.

\section{COMPLEXOS DE ZINCO(II) E MANGANÊS(II) COM GLIFOSATO}

Sundaram e Sundaram ${ }^{13}$, partindo de um procedimento semelhante ao da síntese do complexo de cobre(II) ${ }^{8}$, sintetizaram os complexos de zinco(II) e de manganês(II). As estruturas dos complexos foram assumidas como semelhantes à do complexo de cobre(II). Estudos estruturais destes complexos não foram realizados. Tanto os produtos de solubilidade (Kps) quanto as constantes de estabilidade destes complexos foram determinados com o mesmo procedimento utilizado para o complexo de cobre(II). Os valores de Kps obtidos por Sundaram e Sundaram ${ }^{13}$ estão na Tabela 3. As constantes de estabilidade determinadas por Madsen e colaboradores $^{16}$ estão na Tabela 2.

Em 2000, Kobylecka e colaboradores ${ }^{33}$ estudaram o complexo de zinco(II) com glifosato, através de análise térmica, espectroscopia de IR e difração de Raios-X. A espectroscopia de UV não foi aplicada, uma vez que a solução deste complexo não apresenta bandas de absorção na faixa de 200 a $300 \mathrm{~nm}$. A constante de estabilidade do composto foi determinada pelo método descrito na literatura $^{34}$ e obteve-se o valor de $\log \mathrm{K}$ igual a 7,61. O valor encontrado pelos autores foi menor que o encontrado por Madsen e colaboradores $^{16}(\log K=8,4)$. A solubilidade do complexo em água foi determinada e o valor encontrado foi $8,81 \times 10^{-4} \mathrm{~mol} \mathrm{~L}^{-1}$. Um novo procedimento foi utilizado para síntese deste complexo, em meio ligeiramente ácido; a análise de elementos $(\mathrm{C}, \mathrm{H}, \mathrm{N})$ mostrou que zinco(II) e glifosato reagem na proporção de 1:1 e os dados da difração de Raios-X indicaram que o complexo formado se apresenta cristalino e sem água de cristalização, conforme confirmado por análise térmica. As principais bandas de IR investigadas estão na Tabela 6. O estudo eletroquímico do complexo de zinco(II) foi feito por Glass ${ }^{2}$, através de polarografia de pulso diferencial (DDP) com eletrodo gotejante de mercúrio (DME). Infelizmente, este complexo não apresentou eletroatividade, ou seja, não houve formação de uma onda polarográfica para o complexo de zinco.

\section{COMPLEXOS DE CÁDMIO(II) E CHUMBO(II) COM GLIFOSATO}

Kobylecka e colaboradores ${ }^{33}$ também estudaram os complexos de cádmio(II) e chumbo(II) com o herbicida. Para síntese do complexo de cádmio(II) foi utilizado o mesmo procedimento da síntese do complexo de zinco(II), e o complexo de chumbo(II) foi sintetizado por um procedimento semelhante ao usado por Subramaniam e Hoggard ${ }^{8}$. A análise elementar $(\mathrm{C}, \mathrm{H}, \mathrm{N})$ mostrou que o glifosato 
Tabela 6. Principais bandas de IV $\left(\mathrm{cm}^{-1}\right)$ para complexos metálicos com glifosato

\begin{tabular}{lcccc}
\hline Grupos & Glifosato & Zn(II)-glifosato & Pb(II)-glifosato & Cd(II)-glifosato \\
\hline$v(\mathrm{C}=\mathrm{O})_{\mathrm{COOH}}$ & 1732 & - & - & - \\
$v(\mathrm{C}=\mathrm{O})_{\mathrm{COO}}{ }^{-}$assim. & - & 1618,2 & 1635,5 & 1635,5 \\
$v(\mathrm{C}=\mathrm{O})_{\mathrm{COO}}{ }^{-}$sim. & - & 1407,9 & 1386,7 & 1379,0 \\
$v(\mathrm{~N}-\mathrm{H})$ & - & - & - & - \\
$v\left(\mathrm{~N}^{+} \mathrm{H}_{2}\right)$ & 1568,4 & 1560,3 & 1558,4 & 1558,4 \\
& 798,5 & 792,7 & 798,5 & 783,0 \\
$v(\mathrm{P}=\mathrm{O})$ & 1093,6 & 1099,3 & 1143,7 & 1070,4 \\
& 1031,8 & 1008,7 & 1012,6 & 991,3 \\
\hline
\end{tabular}

reage com cádmio(II) e chumbo(II) na proporção de 1:1, da mesma forma que para o complexo de zinco(II).

$\mathrm{O}$ estudo do comportamento complexante em solução, por espectroscopia de UV, não foi possível para o complexo de cádmio(II) porque, da mesma forma que o complexo de zinco(II), ele não apresenta bandas de absorção na região de 200 a 300 nm. Entretanto, para o complexo de chumbo(II) com glifosato espectros de UV foram registrados e a banda de absorção em $230 \mathrm{~nm}$ foi atribuída ao complexo de composição 1:1. O complexo formado é estável em pH maior que 6,5.

A constante de estabilidade do complexo de chumbo(II) foi determinada pelo método de Job's e foi encontrado o valor de $\log \mathrm{K}=$ 5,9. Para o complexo de cádmio(II) foi utilizado o mesmo método que para o complexo de zinco(II) ${ }^{34}$, e o valor encontrado foi $\log \mathrm{K}=4,94$. A solubilidade destes complexos em água foi determinada e os valores encontrados foram $7,28 \times 10^{-5}$ e $2,55 \times 10^{-3} \mathrm{~mol} \mathrm{~L}^{-1}$ para os complexos de chumbo(II) e cádmio(II), respectivamente. $\mathrm{O}$ método de difração de Raios-X foi aplicado e verificou-se que ambos os complexos se apresentam cristalinos. A análise térmica mostrou que o complexo de chumbo(II) não apresenta água de cristalização em sua estrutura, diferentemente do complexo de cádmio(II) que apresenta duas moléculas de água. As freqüências de IR obtidas para estes complexos estão na Tabela 6.

Os complexos de chumbo(II) e cádmio(II) foram estudados eletroquimicamente por Glass ${ }^{2}$. Soluções com diferentes proporções de metal(II)/glifosato foram analisadas por polarografia de pulso diferencial com eletrodo gotejante de mercúrio. Tal como o complexo de zinco(II), o complexo de chumbo(II) não apresentou eletroatividade. Já o complexo de cádmio(II) apresentou duas ondas polarográficas, uma com potencial de meia-onda $\left(\mathrm{E}_{1 / 2}\right)$ igual a $-0,62 \mathrm{~V}$ referente ao cádmio(II) livre e a outra, referente ao cádmio complexado com $\mathrm{E}_{1 / 2}$ igual a -1,04 V. O complexo de cádmio mostrou-se dependente do valor de $\mathrm{pH}$. Dados adicionais encontrados por Glass ${ }^{2}$ estão na Tabela 7.

Recentemente, Ramstedt e colaboradores ${ }^{35}$ avaliaram o complexo de cádmio(II) com o herbicida através de estudos termodinâmicos e espectroscópicos.
A especiação e o equilíbrio do sistema cádmio(II)-glifosato foram estudados em meio $0,1 \mathrm{M}$ de $\mathrm{NaCl}$. As constantes de formação para uma série de complexos mononucleares, $\mathrm{Cd}(\mathrm{HL}),(\mathrm{CdL})^{-},\left(\mathrm{CdL}_{2}\right)^{-}$ ${ }^{4}$ e $\mathrm{CdL}(\mathrm{OH})^{-2}$, foram determinadas a partir de titulação potenciométrica. As estruturas das espécies predominantes (CdL) e $\left(\mathrm{CdL}_{2}\right)^{-4}$ em solução foram investigadas usando EXAFS e IR. No complexo 1:1 as ligações são formadas entre o Cd(II) e os três grupos doadores (amino, carboxilato e fosfonato) da molécula de glifosato, resultando em dois anéis quelatos de cinco membros (semelhante ao do complexo de $\mathrm{Cu}(\mathrm{II})$ ). No complexo 1:2 os três sítios remanescentes do octaedro distorcido são ocupados pelos grupos de uma segunda molécula de glifosato.

Além disso, uma fase sólida consistindo de cristais de $\mathrm{Cd}_{9}$ (glifosato) ${ }_{6}\left(\mathrm{H}_{2} \mathrm{O}\right)_{12} \cdot 6 \mathrm{H}_{2} \mathrm{O}$ foi sintetizada em meio levemente alcalino e sua estrutura determinada. Esta estrutura consiste de seis octaedros de $\left(\mathrm{CdL}^{-}\right)$conectados por um sétimo octaedro $\mathrm{Cd}-\mathrm{O}$ no centro da unidade, com dois octaedros de $\mathrm{Cd}-\mathrm{O}$ adicionais localizados nos ápices da unidade formada. A Figura 5 representa um dos íons $\mathrm{Cd}(\mathrm{II})$ na estrutura do $\mathrm{Cd}_{9}$ (glifosato) $)_{6}\left(\mathrm{H}_{2} \mathrm{O}\right)_{12} \cdot 6 \mathrm{H}_{2} \mathrm{O}$.

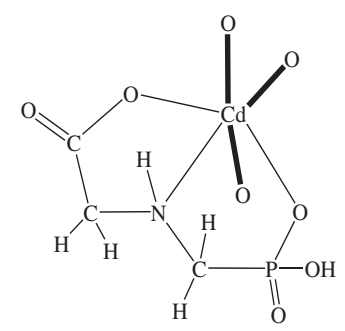

Figura 5. Representação de uma unidade contendo um íon Cd(II) na estrutura do complexo $\mathrm{Cd}_{9}$ (glifosato $)_{6}\left(\mathrm{H}_{2} \mathrm{O}\right)_{12} \cdot 6 \mathrm{H}_{2} \mathrm{O}$

\section{COMPLEXOS DE FERRO(III) E NIQUEL(II) COM GLIFOSATO}

Subramaniam e Hoggard ${ }^{8}$ sintetizaram estes complexos de maneira semelhante ao procedimento para síntese do complexo de

Tabela 7. Potenciais de meia-onda $\left[-\left(\mathrm{E}_{1 / 2}\right)\right]$ e correntes limites $\left(\mathrm{i}_{\mathrm{d}}\right)$ para a redução polarográfica de cádmio(II) livre e complexado com glifosato. Reproduzida da ref. 2, com permissão da ACS

\begin{tabular}{ccccccc}
\hline $\begin{array}{c}\text { Concentração de } \\
\text { cádmio(II) }(\mathrm{mM})\end{array}$ & $\begin{array}{c}\text { Concentração de } \\
\text { glifosato }(\mathrm{mM})\end{array}$ & $\mathrm{pH}$ & $-\left(\mathrm{E}_{1 / 2}\right)_{\mathrm{M}}{ }^{\mathrm{a} / \mathrm{V}}$ & $\mathrm{i}_{\mathrm{d}} / \mathrm{mA}$ & $-\left(\mathrm{E}_{1 / 2}\right)_{\mathrm{C}}{ }^{\mathrm{b} / \mathrm{V}}$ & $\mathrm{i}_{\mathrm{d}} / \mathrm{mA}$ \\
\hline 1,0 & 0,0 & 7,5 & 0,62 & 1,6 & - \\
1,0 & 1,0 & 7,5 & 0,62 & 1,5 & 0,72 \\
1,0 & 2,0 & 7,5 & 0,62 & 1,2 & 0,72 \\
2,6 & 50,0 & 6,5 & $\mathrm{ND}$ & - & 0,72 \\
\hline
\end{tabular}

-( $\left.\mathrm{E}_{1 / 2}\right)$ x SCE (Eletrodo de calomelano saturado); ${ }^{\text {a }}$ potencial de meia-onda do cádmio(II) livre e ${ }^{\mathrm{b}}$ complexado com glifosato; ND: nãodetectável e D: detectável. 
cobre(II), diferindo somente na quantidade de glifosato e íons metálicos que, no caso, foi de 2:1. Um precipitado verde, pouco solúvel em água, formou-se quando foram misturadas as soluções de níquel e glifosato, e no caso do complexo de ferro(III) formou-se um precipitado amarelo, insolúvel em água, álcoois e dimetilformamida. Os sólidos foram analisados por difração de Raios-X e a presença de picos bem definidos confirmou sólidos cristalinos. As freqüências de IR obtidas estão na Tabela 8 .

Tabela 8. Freqüências de IR $\left(\mathrm{cm}^{-1}\right)$ para os complexos de níquel(II) e ferro(III) com glifosato. Reproduzida da ref. 8, com permissão da ACS

\begin{tabular}{lccc}
\hline Modo & $\mathrm{H}_{3} \mathrm{~L}$ & $\mathrm{Na}\left[\mathrm{Ni}(\mathrm{L})\left(\mathrm{H}_{2} \mathrm{O}\right)_{2}\right] .0,5 \mathrm{H}_{2} \mathrm{O}$ & {$\left[\mathrm{Fe}(\mathrm{L})\left(\mathrm{H}_{2} \mathrm{O}\right)_{2}\right] \cdot 1,25 \mathrm{H}_{2} \mathrm{O}$} \\
\hline $\mathrm{v}_{\text {as }}\left(\mathrm{CO}_{2}\right)$ & 1734 & 1600 & 1621 \\
$\delta \mathrm{NH}_{2}$ & 1563 & $*$ & $*$ \\
$\mathrm{v}_{\mathrm{s}}\left(\mathrm{PO}_{3}\right)$ & 981 & 975 & 994 \\
$\mathrm{v}_{\text {as }}\left(\mathrm{PO}_{3}\right)$ & 1094 & 1129 & 1136 \\
& 1159 & &
\end{tabular}

$\mathrm{H}_{3} \mathrm{~L}$ refere-se ao glifosato com seus três hidrogênios. *Encoberta pelo forte estiramento da banda carboxilato

Segundo os autores, estes complexos apresentam uma geometria octaédrica, tendo o glifosato como ligante tetradentado e duas moléculas de água fechando a esfera de coordenação.

$\mathrm{O}$ complexo $\left[\mathrm{Fe}(\mathrm{L})\left(\mathrm{H}_{2} \mathrm{O}\right)_{2}\right] .1,25 \mathrm{H}_{2} \mathrm{O}$ teve seu produto de solubilidade calculado por Sundaram e Sundaram ${ }^{13}$ através do mesmo procedimento utilizado para o complexo de cobre(II) com glifosato. Os valores de Kps em água e diferentes tipos de solos estão na Tabela 3.

Em 1988, Glass² estudou a complexação de glifosato com ferro(III) por um procedimento semelhante ao utilizado no estudo da complexação de cobre(II) com glifosato, usando óxido de ferro(III). Várias soluções em diferentes concentrações de glifosato foram adicionadas a uma certa quantidade de óxido de ferro(III) e, após agitação e centrifugação, registraram-se os espectros destas soluções na região do UV, sendo observada uma banda intensa em 233 nm, referente à transferência de carga glifosato $\rightarrow$ ferro(III).

O comportamento dos complexos de $\mathrm{Ni}(\mathrm{II})$ com glifosato em solução foi estudado por Prenesti e Gulmini ${ }^{36}$ em 1998. As constantes de estabilidades foram calculadas e os valores obtidos estão na Tabela 9.

Tabela 9. Valores das constantes de formação dos complexos de níquel(II)-glifosato

\begin{tabular}{lr}
\hline Complexo & $\log \mathrm{K}$ \\
\hline $\mathrm{NiLH}$ & 13,34 \\
$(\mathrm{NiL})^{-}$ & 8,08 \\
$\left(\mathrm{NiL}_{2}\right)^{-4}$ & 12,48 \\
$\left(\mathrm{Ni}_{2} \mathrm{~L}^{+}\right.$ & 9,48 \\
\hline
\end{tabular}

Foram feitas medidas espectroscópicas na região do visível para soluções com razão glifosato/níquel(II) $\geq 1$. Os valores de $\varepsilon_{\max }$ para os complexos NiLH, (NiL)- e $\left(\mathrm{NiL}_{2}\right)^{-4}$ foram muito pequenos, como esperado para complexos octaédricos de níquel(II), como consequiência, a partir destes espectros não foi possível se formular uma hipótese estrutural, entretanto algumas considerações foram feitas: os complexos NiLH e (NiL)', por possuírem $\lambda_{\text {max }}$ próximos $(650$ $\mathrm{nm}$ ), provavelmente possuem uma estrutura similar; já o complexo $\left(\mathrm{NiL}_{2}\right)^{-4}$ possui $\lambda_{\text {max }}=610 \mathrm{~nm}$, sugerindo uma modificação na esfera de coordenação do complexo (NiL)', devido a rearranjo dos grupos doadores no ligante glifosato.

\section{COMPLEXOS DE ÍONS ALCALINOS TERROSOS COM GLIFOSATO}

Complexos de íons de cálcio e magnésio com glifosato foram sintetizados por Subramaniam e Hoggard ${ }^{8}$ também por um mecanismo semelhante ao da síntese do complexo de cobre(II). Foram obtidos precipitados brancos, insolúveis em água e solventes orgânicos. Os sólidos eram cristalinos e possuiam fórmulas estruturais semelhantes - $\mathrm{Ca}(\mathrm{HL}) \cdot 2,25 \mathrm{H}_{2} \mathrm{O}$ e $\mathrm{Mg}(\mathrm{HL}) \cdot 2,25 \mathrm{H}_{2} \mathrm{O}$.

Sundaram e Sundaram ${ }^{13}$ também calcularam os produtos de solubilidade destes complexos, similarmente ao proposto para o complexo de cobre(II). Os valores do Kps destes complexos em água e diferentes tipos de solo estão na Tabela 3. Madsen e colaboradores ${ }^{16}$ calcularam as constantes de estabilidade para os complexos de cálcio e magnésio em solução (similarmente ao utilizado para o complexo de cobre(II)). Os valores destas constantes estão na Tabela 2.

Sagatys e colaboradores ${ }^{37}$ sintetizaram complexos de bário, estrôncio, cálcio e magnésio com glifosato utilizando método descrito por Rudolf e colaboradores ${ }^{38}$, que consiste na reação, à temperatura ambiente, de quantidades equimolares de glifosato e os respectivos sais dos metais, juntamente com etanol e uréia. Depois da reação, surge um precipitado branco, que pode ser dissolvido com ácido nítrico concentrado. Os complexos obtidos foram caracterizados através de IR e difração de Raio-X. Estes complexos apresentam fórmula geral $\left[\mathrm{M}(\mathrm{HL}) \cdot 2 \mathrm{H}_{2} \mathrm{O}\right]$. $\mathrm{O}$ glifosato de bário bihidratado é um polímero baseado num dímero centrossimétrico $\left\{\left[\mathrm{Ba}(\mathrm{HL})\left(\mathrm{H}_{2} \mathrm{O}\right)_{2}\right]_{2}\right\}$ que se repete, com cada centro irregular de $\mathrm{BaO}_{8}$ ligado por um bis(glifosato). Duas moléculas de água completam a coordenação com o íon $\mathrm{Ba}^{2+}$. A espectroscopia de IR foi utilizada para mostrar que os complexos de Ba e Sr são similares, mas ambos diferem significativamente do complexo de $\mathrm{Ca}$ de fórmula geral $\left\{\left[\mathrm{Ca}(\mathrm{HL})\left(\mathrm{H}_{2} \mathrm{O}\right)_{2}\right]_{2}\right\}_{\mathrm{n}}$ e do complexo de $\mathrm{Mg}$ de fórmula $\left[\mathrm{Mg}_{4}\left(\mu_{3}-\right.\right.$ $\left.\mathrm{OH})_{4}\left(\mathrm{H}_{2} \mathrm{O}\right)_{12}\right]$ e $\left[\mathrm{Mg}_{2}(\mathrm{~L})_{2}(\mu-\mathrm{HL})\left(\mathrm{H}_{2} \mathrm{O}\right)_{2}\right]$.

\section{COMPLEXOS DE CROMO(III) E COBALTO(III)}

Heineke e colaboradores ${ }^{5}$ sintetizaram e caracterizaram complexos de cobalto(III) e cromo(III) com o herbicida. Para síntese do complexo $\left[\mathrm{Co}(\mathrm{L})_{2}\right]^{-3}$ foram utilizados dois procedimentos. No primeiro, uma certa quantidade de $\mathrm{Na}_{3} \mathrm{Co}\left(\mathrm{CO}_{3}\right)_{3}$ (este complexo de cobalto(III) foi sintetizado de acordo com o procedimento descrito na literatura ${ }^{39}$ ) foi adicionada a uma solução de glifosato, resultando no complexo $\mathrm{Na}_{3} \mathrm{Co}(\mathrm{L})_{2}$. No segundo procedimento, uma solução de glifosato (em meio de $\mathrm{NaOH} 0,1 \mathrm{~mol} \mathrm{~L}^{-1}$ ) foi misturada a uma solução de $\mathrm{CoCl}_{2} \cdot 6 \mathrm{H}_{2} \mathrm{O}$, seguida da adição de $\mathrm{H}_{2} \mathrm{O}_{2}$ para oxidação do $\mathrm{Co}(\mathrm{II})$ a $\mathrm{Co}(\mathrm{III})$, resultando no complexo $\left(\mathrm{NH}_{4}\right)_{3} \mathrm{Co}(\mathrm{L})_{2}$. Nos dois procedimentos a solução resultante apresentou uma mistura de isômeros, com o glifosato na forma de ligante tridentado $\left(\mathrm{L}^{-3}\right)$. O complexo $\left[\mathrm{Co}(\mathrm{L})_{2}\right]^{-3}$ também foi sintetizado a partir de uma solução de glifosato em $\mathrm{NH}_{3}$, resultando no complexo $\left(\mathrm{NH}_{4}\right)_{3} \mathrm{Co}(\mathrm{L})$; o sólido obtido, ao contrário dos demais complexos metálicos de glifosato, é solúvel em água, e chega a ser altamente deliqüescente, o que não possibilitou a caracterização por microanálise. $\mathrm{O}$ estudo por Ressonância Magnética Nuclear de Hidrogênio (RMN-H) mostrou a presença dos mesmos isômeros do complexo $\mathrm{Na}_{3} \mathrm{Co}(\mathrm{L})_{2}$. O complexo de $\mathrm{Cr}$ (III) foi obtido a partir da mistura de uma solução de glifosato com uma solução de $\mathrm{CrCl}_{3} \cdot 3 \mathrm{H}_{2} \mathrm{O}$, resultando o complexo $\mathrm{Na}_{3} \mathrm{Cr}(\mathrm{L})_{2}$. Depois da evaporação do solvente resultou um sólido azul, que foi considerado impuro após microanálise. O es- 
pectro de UV deste sólido em água mostrou a presença de duas fortes bandas de absorção, uma em 412 e a outra em $562 \mathrm{~nm}$.

Os isômeros estruturais do complexo de cobalto(III) não são separáveis devido a sua rápida interconversão. Estudos de espectroscopia de UV e Ressonância Magnética Nuclear de Hidrogênio (RMN-H) foram utilizados para caracterizar estes complexos. A representação estrutural destes complexos está na Figura 6.

A razão dos isômeros do complexo de cobalto(III), encontrada por Heineke e colaboradores ${ }^{5}$, para os isômeros 1, 2, 3, 4, 5, 6 e 7 foi 7,1 : 5,0:13,8:4,0:2,6:2,0:1,0. A abundância relativa do isômero 8 não pôde ser determinada, devido à baixa concentração. Alguns dados do estudo espectroscópico na região do UV estão na Tabela 10.

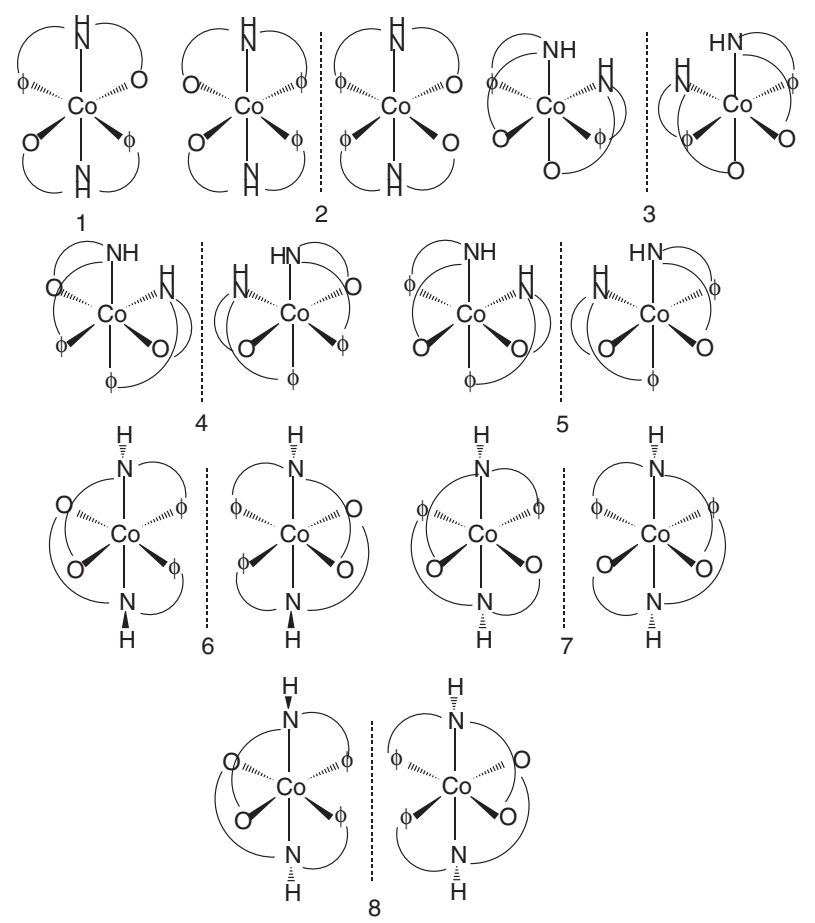

Figura 6. Esquema dos possíveis isômeros do complexo de cobalto(III) com glifosato. $\Phi$ representa $\mathrm{CH}_{2} \mathrm{PO}_{3}^{-2}$ e O representa $\mathrm{CH}_{2} \mathrm{CO}_{2}$. Reproduzida da ref. 5, com permissão da ACS

Tabela 10. Absorção máxima dos complexos de $\mathrm{Cr}$ (III) com glifosato. Reproduzida da ref. 5, com permissão da ACS

\begin{tabular}{lc}
\hline Isômero & Absorção Máxima, nm \\
\hline Isômero 1 & $381,518,662$ \\
Mistura dos isômeros em $\mathrm{H}_{2} \mathrm{O}$ & $397,528,620$ \\
Mistura dos isômeros em $\mathrm{H}_{2} \mathrm{O} /$ Etanol & $400,536,604$ \\
Complexos de cromo(III) & 412,562 \\
\hline
\end{tabular}

\section{COMPLEXOS DE LANTANÍDEOS COM GLIFOSATO}

Em 2001, Ptaszynski e Zwolinska ${ }^{40}$ sintetizaram complexos solúveis de alguns lantanídeos - La(III), Ce(III), Nd(III) e $\mathrm{Er}(\mathrm{III})$ de fórmulas gerais $\mathrm{La}(\mathrm{L}) \cdot \mathrm{H}_{2} \mathrm{O}, \mathrm{Ce}(\mathrm{L}) \cdot \mathrm{H}_{2} \mathrm{O}, \mathrm{Nd}(\mathrm{L}) .1,5 \mathrm{H}_{2} \mathrm{O}$ e $\mathrm{Er}(\mathrm{L}) \cdot 2 \mathrm{H}_{2} \mathrm{O}$. A solubilidade em água foi determinada e análises de IR, difratométricas e térmicas foram realizadas para caracterização de tais complexos. Estes autores observaram que estes íons de lantanídeos se ligam ao glifosato através dos átomos de oxigênios dos grupos carboxilato, fosfonato e, também, através do nitrogê- nio do grupo amino. Outros estudos em relação a estes complexos ainda não foram realizados.

\section{COMPLEXOS DE AMÔNIO, LÍTIO, SÓDIO E PRATA(I) COM GLIFOSATO}

Sagatys e colaboradores ${ }^{41}$ sintetizaram alguns complexos de metais(I) e também do íon amônio. Os complexos obtidos por eles foram $\mathrm{NH}_{4}\left(\mathrm{H}_{2} \mathrm{~L}\right), \quad \mathrm{Li}\left(\mathrm{H}_{2} \mathrm{~L}\right), \mathrm{Ag}_{2}(\mathrm{HL})$ e os polimorfos $\mathrm{Na}\left(\mathrm{H}_{2} \mathrm{~L}\right) \cdot 0,5 \mathrm{H}_{2} \mathrm{O}, \mathrm{Na}\left(\mathrm{H}_{2} \mathrm{~L}\right) \cdot \mathrm{H}_{2} \mathrm{O}, \mathrm{Na}\left(\mathrm{H}_{2} \mathrm{~L}\right) \cdot 2,0 \mathrm{H}_{2} \mathrm{O}, \mathrm{Na}_{2}(\mathrm{HL}) \cdot 9,0 \mathrm{H}_{2} \mathrm{O}$. Estes complexos foram caracterizados por IR e, alguns deles, por difração de Raios-X.

$\mathrm{O}$ complexo $\mathrm{NH}_{4}\left(\mathrm{H}_{2} \mathrm{~L}\right)$ consiste de um hidrogênio ligado numa estrutura entrelaçada na qual todos os prótons do $\mathrm{NH}_{4}^{+}$estão envolvidos na ligação de hidrogênio, juntamente com o grupo amino e um próton do fosfonato. Os complexos polimorfos de sódio $\mathrm{Na}\left(\mathrm{H}_{2} \mathrm{~L}\right) \cdot 0,5 \mathrm{H}_{2} \mathrm{O}$ e $\mathrm{Na}\left(\mathrm{H}_{2} \mathrm{~L}\right) \cdot \mathrm{H}_{2} \mathrm{O}$ são poliméricos e baseados num dímero que se repete com seis centros de sódio coordenados. $\mathrm{O}$ complexo $\mathrm{Na}_{2}(\mathrm{HL}) \cdot 9,0 \mathrm{H}_{2} \mathrm{O}$ consiste de unidades de um complexo aniônico octaédrico $\left[\mathrm{Na}(\mathrm{HL}) . \mathrm{H}_{2} \mathrm{O}\right]$, com o glifosato atuando como ligante unidentado ligado a partir de um oxigênio do carboxilato ao polímero catiônico $\left[\mathrm{Na}_{2}\left(\mathrm{H}_{2} \mathrm{O}\right)_{8}\right]^{+2}$. Todos estes complexos apresentam ligações de hidrogênio. $\mathrm{O}$ complexo de $\mathrm{Ag}_{2}(\mathrm{HL})$ é uma estrutura polimérica que envolve o fosfonato ligado a uma cadeia linear através do grupo carboxilato e um íon $\mathrm{Ag}^{+}$coordenado com os oxigênios do outro grupo fosfonato.

\section{CONCLUSÃO}

Os complexos de cobre(II) com glifosato foram amplamente estudados e caracterizados quanto a sua estrutura e estabilidade devido, principalmente, à importância do cobre para plantas e animais. Outros íons de metais de transição tiveram suas reações com o herbicida investigadas em menor extensão (síntese e caracterização estrutural), restando vários íons importantes a serem pesquisados, como por ex. $\mathrm{Al}(\mathrm{III})$.

O estudo das propriedades complexantes do glifosato pode ser justificada não somente pelo interesse químico mas, também, porque as informações obtidas através das pesquisas são essenciais para compreensão do comportamento deste herbicida no solo e nas plantas.

\section{AGRADECIMENTOS}

À CAPES pela bolsa de pesquisa utilizada durante a execução deste trabalho.

\section{REFERÊNCIAS}

1. Daniele, P. G.; Stefano, C.; Prenesti, E.; Sammartano, S.; Talanta 1997, $45,425$.

2. Glass, R. L.; J. Agric. Food Chem. 1984, 32, 1249.

3. Hoagland, R. E.; Duke, S. O.; ACS Symp. Ser. 1982, 181.

4. Kaliannan, P.; Ali, M. M. N.; Seethalakshmi, T.; Venuvanalingam. P.; J. Mol. Struct. 2002, 618, 117.

5. Heineke, D.; Frankllin, S. J.; Raymond, K. N.; Inorg. Chem. 1994, 33, 2413.

6. Morillo, E.; Undabeytia, T.; Maqueda, C.; Ramos, A.; Chemosphere 2000, $40,103$.

7. Barja, B. C.; Herszage, J.; Afonso, M. S.; Polyhedron 2001, 20, 1821.

8. Subramaniam, V.; Hoggard, P. E.; J. Agric. Food Chem. 1988, 36, 1326.

9. Baley, W. A.; Poston, D. H.; Wilson, H. P.; Hines, T. E.; Weed Tech. 2002, 16,792 .

10. Wills, G. D.; McWhorter, C. G.; Weed Tech. 1985, 33, 755.

11. Sprankle, P.; Meggitt, W. F.; Penner, D.; Weed Sci. 1975, 23, 229.

12. Lee, J. D.; Química Inorgânica Não Tão Concisa, $5^{\text {a }}$ ed., Edgard Blücher Ltda: São Paulo, 1999. 
13. Sundaram, A.; Sundaram, K. M. S.; J. Environ. Sci. Health, Part B 1997, 32, 583.

14. Sheals, J.; Pearsson, P.; Hedman. B.; Inorg. Chem. 2001, 40, 4302.

15. Smith, J.V.; Inorganic X-Ray Powder Data File, Americam Society for Testing and Materials: Philadelphia, 1967.

16. Madsen, H. E. L.; Christensen, H. H.; Gottlieb-Petersen, C.; Acta Chemica Scandinavica A 1978, 32, 79.

17. Schindler, P. W.; Equilibrium Concepts in natural Water Systems, American Chemical Society: Washington, DC, 1967.

18. Bronstad, J. O.; Friestad, H. O.; Analyst 1976, 101, 820.

19. Hance, R. J.; J. Soil Sci. 1976, 7, 363.

20. Carlisle, S. M.; Trevors, J. T.; Water, Air, Soil Pollut. 1988, 39, 409.

21. Roy, D. N.; Konar, S. K.; Banerjee, S.; Charles, D. A.; Thompson, D. G.; Prasad, R.; J. Agric. Food Chem. 1989, 37, 437.

22. Piccolo, A.; Celano, G.; Arienzo, M.; Mirabella, A.; J. Environ. Sci. Health, Part B 1994, 29, 1105.

23. Day, G. M.; Hart, B. T.; McKelvie, I. D.; Beckett, R.; Environ. Technol. 1997, 18, 781.

24. Torstensson, L.; Behaviour of Glyphosate in soils and its degradation, Butterworths: London, 1985.

25. McConnell, J. S.; Hossner, L. R.; J. Agric. Food Chem. 1985, 33, 1075.

26. Morillo, E.; Undabeytia, T.; Maqueda, C.; Environ. Sci. Technol. 1997, 31, 3588 .

27. Morillo, E.; Undabeytia, T.; Maqueda, C.; Madrid, L.; Bejarano, M.; Chemosphere 1994, 28, 2185.
28. Buffle, J.; Altamann, R. S.; Filella, M.; Tessier, A.; Geochim. Cosmochim. Acta 1990, 54, 1535.

29. Morillo, E.; Undabeytia, T.; Maqueda, C.; Ramos, A.; Chemosphere 2002, 47, 747

30. Maqueda, C.; Morillo, E.; UndaBeytia, T.; Martín, F.; Chemosphere 1998, $37,1063$.

31. Undabeytia, T.; Cheshire, M. V.; McPhail, D.; Chemosphere 1996, 32, 1245.

32. McBride, M. B.; Soil Sci. Soc. Am. J. 1991, 55, 979.

33. Kobylecka, J.; Ptaszynski, B.; Zwolinska, A.; Monatsh. Chem. 2000, 131,

34. Inczedy, J.; Analytical Applications of Complex Equilibria, Akademia Kiado: Budapest, 1976.

35. Ramstedt, M.; Norgren, C.; Sheals, J.; Boström, D.; Sjöberg, S.; Persson, P.; Inorg. Chim. Acta 2004, 357, 1185.

36. Prenesti, E.; Gulmini, M.; Ann. Chim. 1998, 88, 591.

37. Sagatys, D. S.; Dahlgren, C.; Smith, G.; Bott, R. C.; Willis, A. C.; Aust. J. Chem. 2000, 53, 77

38. Rudolf, P. R.; Clark, E. T.; Martell, A. E.; Clearfield, A.; Acta Crystallogr., Sect. C: Cryst. Struct. Commun. 1988, 44, 535.

39. Collman, J. P.; Kittleman, E. T.; Inorg. Synth. 1966, 8, 149.

40. Ptaszynski, B.; Zwolinska, A.; Pol. J. Environ. Studies 2001, 10, 257.

41. Sagatys, D. S.; Dahlgren, C.; Smith, G.; Bott, R. C.; White, J. M.; J. Chem. Soc., Dalton Trans. 2000, 19, 3404. 